\title{
Editorial
}

\section{Guidance on publishing results and how we operate evidence-based policy}

In the last issue we took up the challenge about institutional structures and systems that are not working to effectively address undernutrition. The present editorial follows on this theme to address two further and related issues: code of practice for publishing and access to raw data; and evidence to policy: who decides?

\section{Code of practice for publishing and access to raw data}

How do we ensure that all studies are treated fairly in the peer review process? What we allude to here is avoidance of publication bias, where those studies that do not conform with the current paradigm about a topic are less likely to be reviewed positively and accepted for publication. The word 'bias' is used to imply that the system does not operate evenly or fairly for all studies. A publication bias would occur if a well-conducted study that showed, for example, no effect of vitamin A supplementation on mortality was rejected for publication because it did not fit with the widely held view that vitamin A supplementation is beneficial in reducing mortality. Bias would occur if the paper was submitted to a journal and was rejected because the reviewer implied the study was flawed because the result did not conform to previous work. There would be a particular concern if conflicting interests were not declared by editors and reviewers in the review process.

Another form of publication bias may arise when the results from a study are withheld from submission for publication. It is unethical not to publish (or withhold) the results of funded (from any source - industry or nonindustry) work. If the work is not sent for publication because the authors (or the funding agency) do not like the findings, this is particularly unacceptable.

Our concern has been raised because of results from the DEVTA study looking at the impact of vitamin A supplementation on mortality - presented at meetings in 2007 (see www.ctsu.ox.ac.uk/projects/devta for details), but not yet published in a peer-reviewed journal suggested that supplementation is of no benefit in reducing mortality. The DEVTA trial which is based on one million children (from Uttar Pradesh, India), very much bigger than the total of all previous trials, and was completed in 2004. As early as 1993, Beaton et al. ${ }^{(1)}$ were cautious in drawing strong conclusions about the links between vitamin A supplementation and mortality. This caution has been expressed by others as well ${ }^{(2)}$. Despite these concerns policy has remained to advocate for supplementation, with lip service being paid to other strategies or the fact that scarce resources may be wasted or diverted away from more effective programmes of work.

Two proposals are put forward to address these issues.

1. All journals need to comply with best practice in declaring competing/conflict of interests in all aspects of the way a journal conducts its business. The International Union of Nutritional Sciences has commissioned a working group to come up with guidelines. Current best practice (see e.g. policy of the British Medical Journal) is that all persons involved in any aspect of running the journal (editors and editorial advisors, reviewers, authors) must declare competing interests and answer a detailed questionnaire on activities over the last five years. There is now growing clarity as to what competing interests represent and the 'rule of thumb' is to be rather more open about declaring interests than has previously been the case. Reviewers with a competing interest should not be involved in reviewing papers. Authors should declare any competing interests, and we believe this should include whether the department or university in which they work receives money from industry or agencies where they may be a competing interest. The Committee of Publication Ethics (COPE) states in their publication 'A code of conduct for editors of bioscience journals' (http://www.publicationethics. org.uk/guidelines/code) that 'Editors should have systems for managing their own conflicts of interest as well as the conflicts of interest of their staff, authors, and reviewers. Readers should be informed about who has funded research and on the role of the funders in the research.' Unless we have those systems in place, we are not taking care of our journals. Public Health Nutrition is a member of COPE.

2. To avoid studies being buried or unreasonably delayed we believe pressure should be exerted by funding bodies and countries that host studies to: (i) keep a register of all studies being conducted; and (ii) make the raw data from such studies open for public access, so that other researchers can analyse 
the results. Such a system is in place in the UK for studies funded by the government. When accepting the funds researchers must agree to do this, and the final payment of the grant is not made until the data are deposited in the archive. Is such a system workable internationally? We suggest that it could be and urge this to be taken up. We also believe that academics working in international nutrition, in particular, have a moral and ethical responsibility to inform hosting country governments of the findings of their research.

\section{Evidence to policy: who decides?}

The above discussion raises the question as to who decides what gets funded. Are the same people involved in making all these decisions? Do we know who these people are and how they acquired their roles? For the various nutrition-related global strategies, who decides who chairs these international panels (single or joint) and who appoints these members? We also feel that beneficiary countries tend to be under-represented on these panels. This is not to imply that the person(s) appointed is (are) not suitable, but it all seems to be conducted in the shadows, and we believe it should be much more in the open. Once the recommendations of these panels are published they often bypass scientific scrutiny from local experts (with valuable and relevant local experience) and go directly to governmental level in the recipient country.

A number of steps need to be articulated and explicit in this process: who constitutes the committee and under what auspices; who selects the members of the committee; are there any rules about who is or is not eligible; how does the process identify any competing interests; how do they go about reviewing the evidence; and what rules are explicit for reaching consensus about recommendations? Perhaps we are misguided, but as far as we are aware these questions are not easily answered and the process is not transparent.

The appointment process of advisors for international decision making should be open and transparent, and all participants should be forced to make a public declaration of any competing interests, being excluded from decision making if any are identified. Any relations with industry (in the widest sense of this term), and with universities or other organisations with a vested interest in the deliberations, must be open and declared - in terms of who funds the process, who appoints, etc. It should also be clear in what capacity people sit on committees, whether they are expressing an individual view, whether they are meant to represent a constituency of some sort, and if so how they canvass the view of that constituency.

This may seem naive and simplistic, but it has been a recurring theme in nutrition that we do not do our business in an open and transparent way. Not only is it unethical, but it also affects our integrity and credibility, to carry on as we have so far to date. If we have nothing to hide, then let the light shine in, so people can see how we do our business. Failure to support this can lead to only one conclusion: we will then get what we deserve nothing, but more importantly we will not be protecting the lives of the innocent.

Agneta Yngve

Editor-in-Chief

Barrie Margetts

Deputy Editor

Email: B.M.Margetts@soton.ac.uk

H.P.S. Sachdev

Senior Consultant in Pediatrics and Clinical Epidemiology Sitaram Bhartia Institute of Science and Research

New Delhi, India

\section{References}

1. Beaton GH, Martorell R, Aronsen KA, Edmonston B, McCabe G, Ross AC \& Harvey B (2003) Vitamin A Supplementation and Child Morbidity and Mortality in Developing Countries. ACC/SCN Nutrition Policy Discussion Paper no. 13. Geneva: WHO.

2. Kapil U \& Sachdev H (2001) National consultation on benefits and safety of administration of vitamin A to preschool children and pregnant and lactating women. Indian Pediatr 38, 37-42. 